\title{
Flexural capacity of RC beams strengthened with near-surface mounted steel bars
}

\author{
Rendy Thamrin $^{1 *}$ and Zaidir Zaidir ${ }^{1}$ \\ ${ }^{1}$ Civil Engineering Department, Engineering Faculty, Andalas University, 25163, Padang, Indonesia
}

\begin{abstract}
An experimental study carried out to observe the flexural capacity of reinforced concrete beams strengthened with Near Surface Mounted (NSM) steel bars is presented. The test was carried out on nine concrete beams. All tested beams were subjected to two-point monotonic loads. The ratio of longitudinal reinforcement (1\%, 1.4\%, and 2.4\%) and NSM bars (1D16 and 2D16) were used as test variables. It was found from the test result that NSM steel bars significantly increase the flexural capacity of reinforced concrete beams. However, the strengthened beams failed in brittle mode, as indicated by a sudden drop of beams capacity. An analytical study was also conducted to obtain the flexural response of the specimens through all ranges of elastic and post-peak load. The prediction of the flexural capacity of the beams compares well with the test result.
\end{abstract}

\section{Introduction}

In recent years, research on retrofitting reinforced concrete structures has resulted in a wide choice of methods that can be used for reinforcement. One category of the strengthening techniques is to increase the amount of reinforcement by attaching steel bars, FRP bars, steel plates, FRP plates, or FRP sheets to the surface of structural members [1]. However, a wrong choice of strengthening method may result in unexpected situations during the structure's service life. The near-surface installation (NSM) method, which is a more practical method, was introduced for strengthening reinforced concrete structures [2,3].

The idea of using the NSM method using either steel or FRP has made this method widely researched and used as a strengthening method [2-12]. Besides increasing the bending capacity of the beam structure [4] strengthening method using NSM with steel bars can also be used to improve the shear capacity of the beams $[5,10]$. Another study reported that steel plates installed using the NSM method made a significant contribution to the shear strength of concrete beams [11]. This method is also proven to protect the environment where the reinforcing bars used as strengthening are covered by a material made of epoxy [6].

The purpose of this paper is to examine the flexural capacity of reinforced concrete beams strengthened with steel bars by applying the NSM method. In addition, the ratio of the appropriate steel bars used for strengthening is also checked using two different ratio values. The theoretical flexural behavior of the beam also needs to be known precisely to obtain the ultimate flexural strength of the beam. In this study, the flexural capacity of the beam was obtained using a computer program that has been developed by the author [7-12].

\section{Experimental Setup}

Nine concrete beams were tested to examine the flexural capacity of strengthened reinforced concrete beams using the NSM method. The test setup and loading arrangement, shown in Fig. 1, offer the equipment used during the test. The test setup consisted of beam specimens placed in simple support and loaded with two-point loads using a $500 \mathrm{kN}$ capacity hydraulic jack and steel spreader beam. The load cell was used to measure the load applied from the hydraulic jack, and LVDT's were used to measure deflections of the test beams. Applied load and deflections were monitored, and the data was stored in a data acquisition system.

The dimension and types of test specimens are shown in Fig. 2. The first type is specimen strengthened with one steel bar, and the second is specimen strengthened with two steel bars. The steel bar diameter used to strengthen the beam was $16 \mathrm{~mm}$ with a yield strength of $476.2 \mathrm{MPa}$. The beams had a clear length of $2000 \mathrm{~mm}$ with a shear span length of $800 \mathrm{~mm}$, as shown in Fig. 2. The beam's cross-section was $125 \times 250 \mathrm{~mm}$, and the size of tensile longitudinal reinforcing bars was $13 \mathrm{~mm}$ with a yield strength of $448.3 \mathrm{MPa}$. The longitudinal reinforcement ratios used were $1 \%, 1.5 \%$, and $2.5 \%$, as shown in Fig. 2 . Compression reinforcement and stirrups with a diameter of $10 \mathrm{~mm}$ and yield stress of $355.2 \mathrm{MPa}$ were used for all test specimens. Fresh concrete was supplied by a readymix company, and the compressive strength of the concrete cylinder at the age of 28 days was $20 \mathrm{MPa}$.

\footnotetext{
* Corresponding author:rendythamrin@eng.unand.ac.id
} 


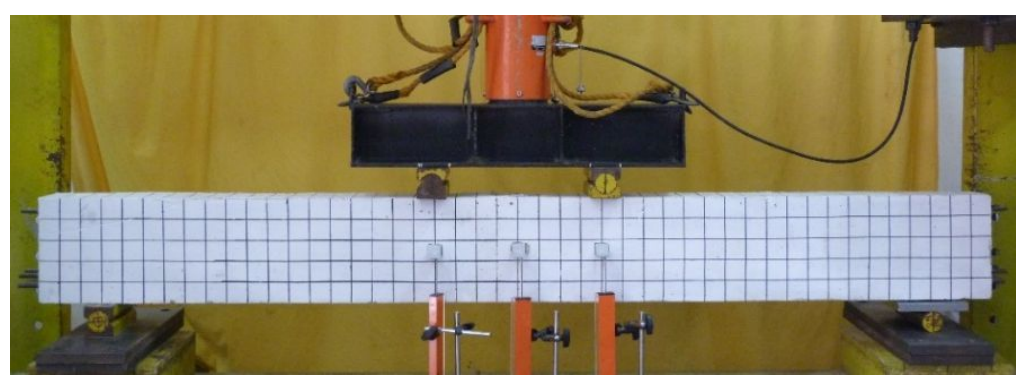

Fig. 1. Test setup and equipment used during the test.

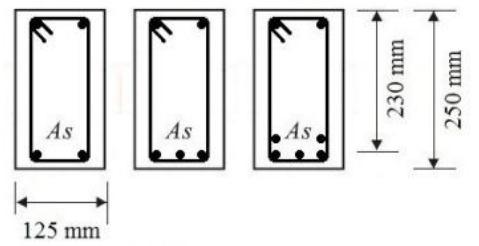

(a) Cross-sections of control beams (G6C1, G6C2, and G6C3).
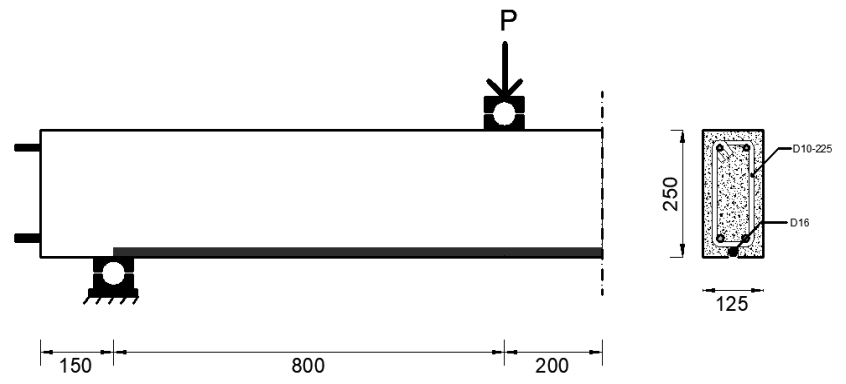

(b) Specimen strengthened with one steel bar (G6R1-1, G6R1-2, and G6R1-3).

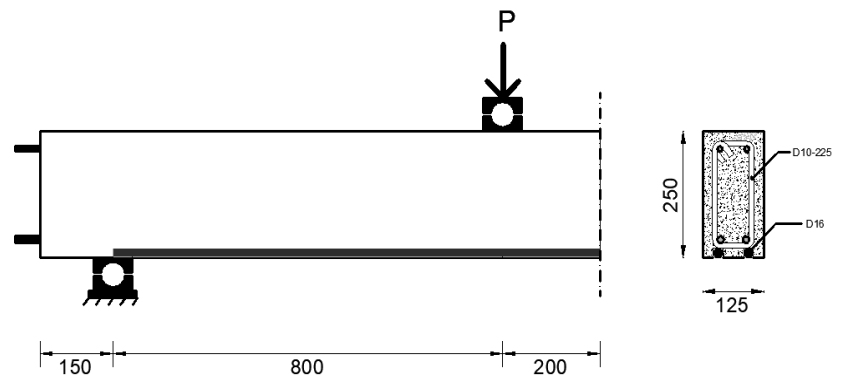

(c) Specimen strengthened with two steel bars (G6R2-1, G6R2-2, and G6R2-3).

Fig. 2. Detail of beam specimens.

The groove cuts were firstly prepared on the bottom side of the wooden formwork. The groove size was $20 \mathrm{~mm}$ wide and $20 \mathrm{~mm}$ deep. The wooden formwork was removed after 28 days, and the groove surfaces were cleaned to remove fine particles and dust. The steel bar installation process for strengthening was preceded by applying epoxy adhesive paste halfway into the grooves using a palette knife. Then the steel bar $(16 \mathrm{~mm})$ was placed on the top of the adhesive layer and pressed lightly along the bar. At the final stage, the grooves were again filled with epoxy adhesive paste, and then the surface was leveled.

The test started by applying an increase in load using a hydraulic jack. The applied load at each step was incremented by approximately $0.1 \mathrm{kN}$. The cracks propagation was mapped during the test, as well as the load and deflections were recorded. Loading increments continued until the specimen failed, indicated by yielding of the tensile reinforcement and crushing of the top fiber of the compression zone.

\section{Analytical Study}

The theoretical capacity of the reinforced concrete crosssection was obtained from a developed computer program by the author [7-13]. The calculation procedure is based on the theoretical moment-of-curvature determination [13]. In this method, the reinforced concrete section is divided into several layers of concrete and reinforcement. The computer program takes into account the nonlinearity of the concrete in the compression zone. The concrete 
stress-strain curve used in the program is adopted from the model proposed by Mander et al. [14]. Meanwhile, the stress-strain curve of steel used is a bilinear model. The maximum concrete strain was assumed as 0.005 . The beam deflections were calculated from the integration of the curvature along the beam length.

\section{Results and Discussion}

In this experimental study, the load was increased by 0.1 $\mathrm{kN}$ at each incremental load. Deflection at a particular position and crack propagation were recorded during the test. Initial flexural cracks developed in the constant moment region between two-point loads. When the load was increased, more flexural cracks were formed in the constant moment region and the shear span zone. Subsequently, the diagonal shear cracks were propagated in both shear-span zones when the load was increased.

All control beams (G6C1, G6C2, and G6C3) were failed in flexural failure mode. This failure mode was indicated by yielding tensile longitudinal reinforcement and crushing of concrete in the constant moment region, as shown in Fig. 3(a-c).

(a) $\mathrm{G} 6 \mathrm{Cl}$

(b) $\mathrm{G} 6 \mathrm{C} 2$

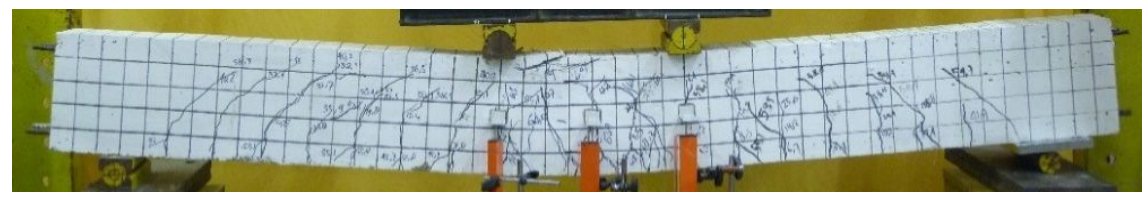

(c) $\mathrm{G} 6 \mathrm{C} 3$

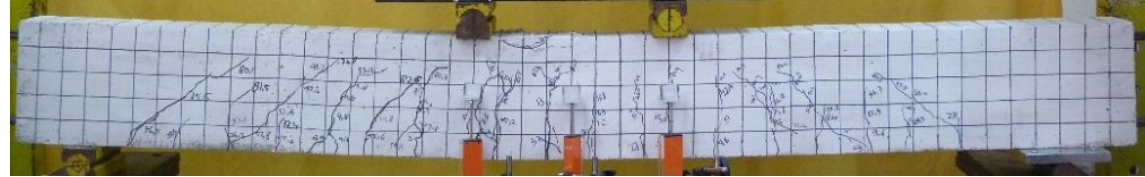

(d) G6R1-1
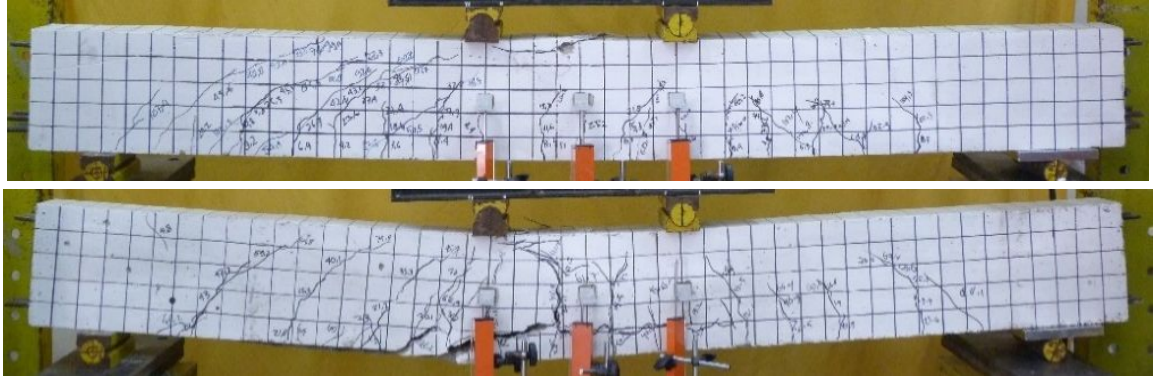

(e) G6R1-2

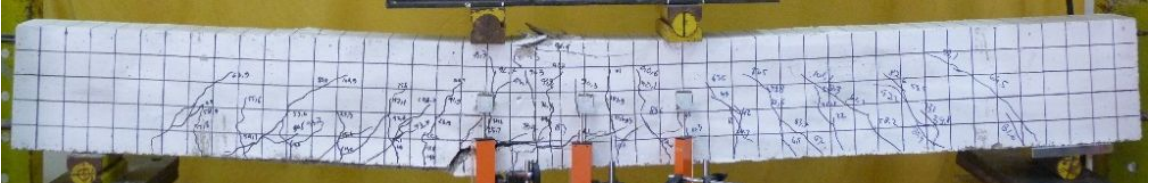

(f) G6R1-3

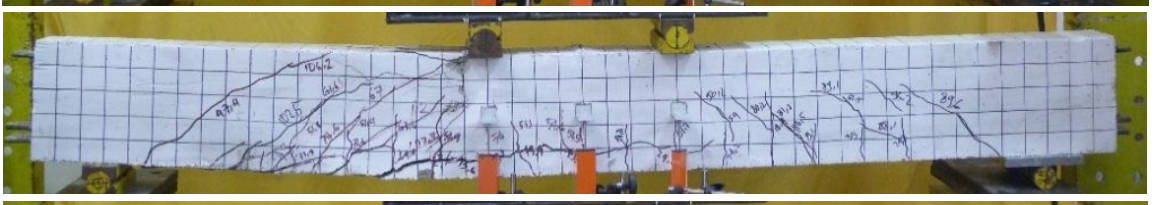

(g) G6R2-1

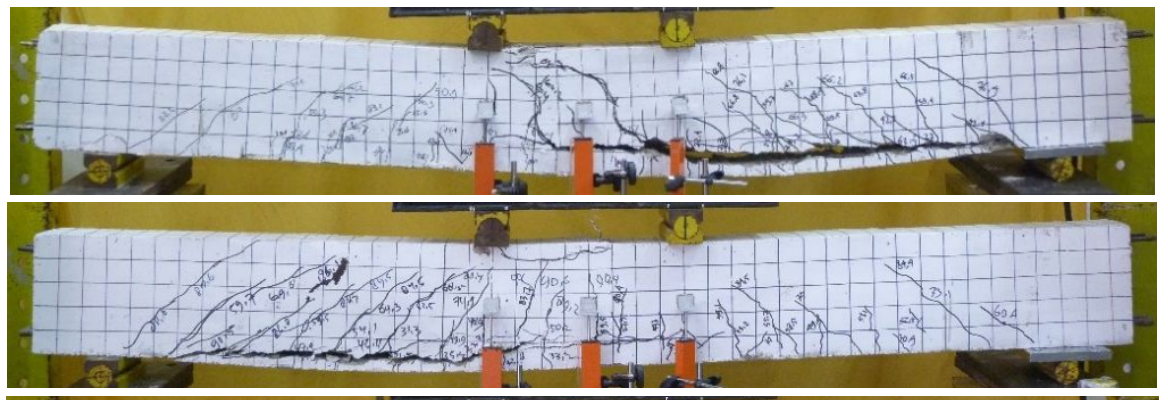

(i) G6R2-3

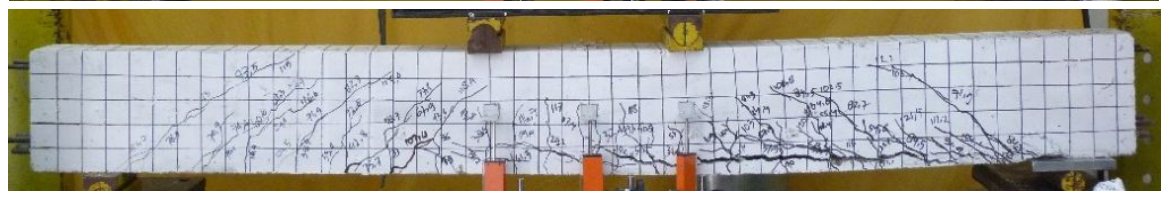

Fig. 3. Crack patterns of the beams.

However, all beams reinforced with steel bars failed immediately after the occurrence of debonding failure. Debonding failure was indicated by the loss of bond between concrete and strengthening bar. Concrete cover separation at the bottom of the beams along the beam length also indicates the debonding failure occurrence, as 
shown in Fig. 4. The effect of strengthening with a steel bar on the beam can be observed from the increase in the value of the first crack load on the strengthened beam.

Fig. 5 shows the load-deflection curves of the tested beams. It can be shown from Fig. 5(a) that as the ratio of reinforcement increases, the capacity of the beams increases, but the ductility decreases. Figs 5(b) and (c) show the sudden drop of the load-deflection curve after the occurrence of debonding failure. In this study, if the debonding failure occurred, the load was uninterruptedly applied until the beam reached concrete crushing at the top surface of the compression zone. It aims to see the behavior of the beam after the debonding failure. It can be seen that after the steel bar's debonding failure, the load immediately drops to the same load level as the control beam.
These curves also show that when the debonding failure occurred, both the strengthening bar and steel reinforcement did not experience yielding. Before the debonding failure, it was seen that the capacity of the strengthened beams slightly exceeded the capacity of the control beams. This proves that the capacity of the strengthened beams is higher than that of the control beams.

Fig. 6 shows a schematic plot of the stress-strain laws of concrete and steel bars used in the analytical study. The theoretical prediction of flexural capacity for each beam specimen is shown in Fig. 7. From these curves, it can be seen that the higher the ratio of longitudinal reinforcement, the more rapid and sudden debonding failure occurs.

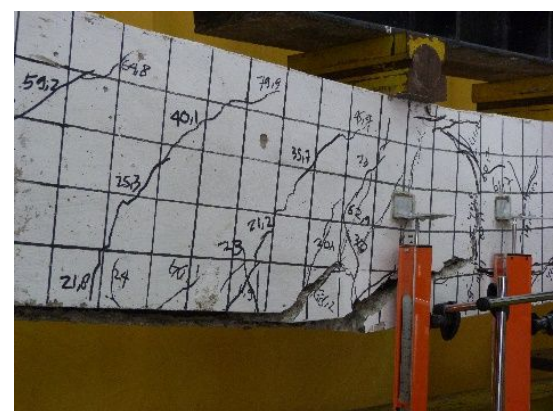

(a) G6R1-1

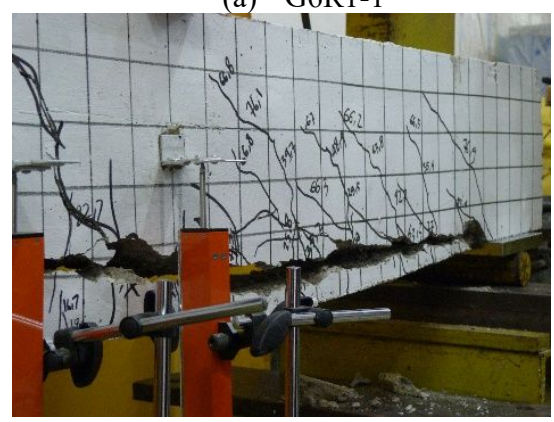

(d) G6R2-1

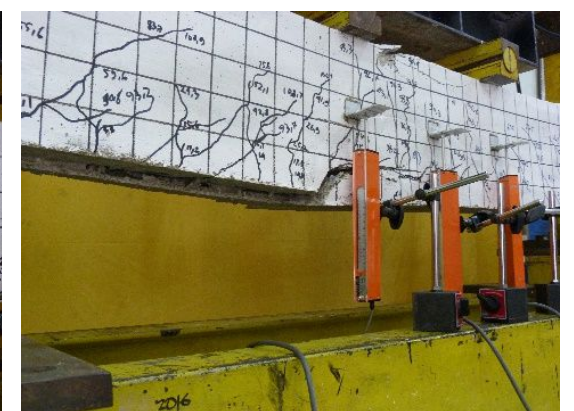

(b) G6R1-2

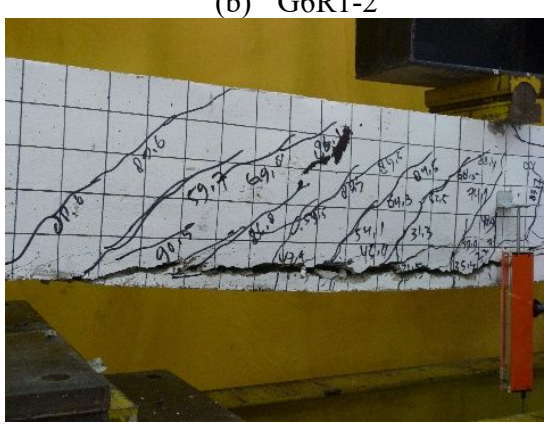

(e) G6R2-2

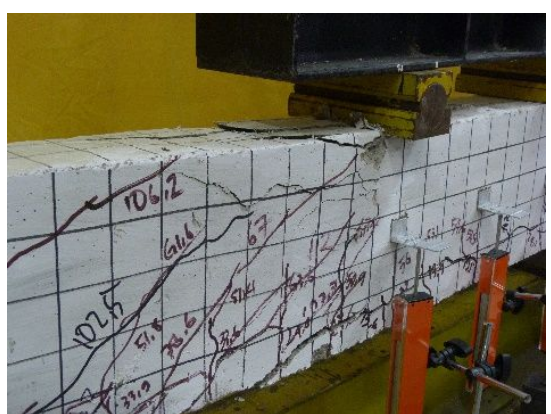

(c) G6R1-3

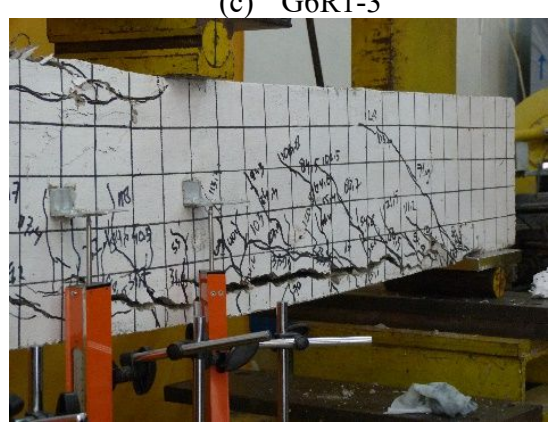

(f) G6R2-3

Fig. 4. Typical debonding failure of strengthened beams.

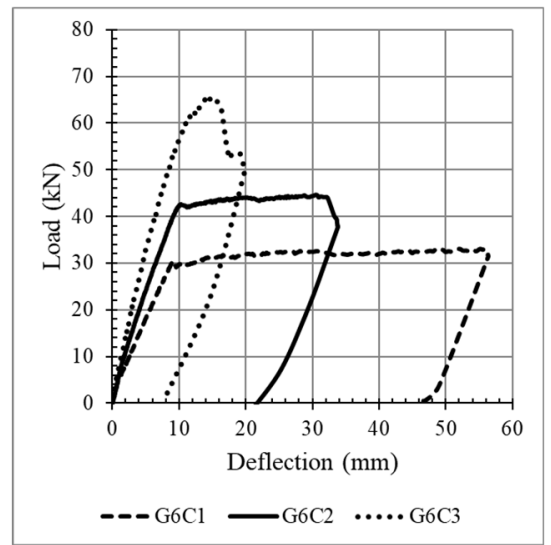

(a) Control beams

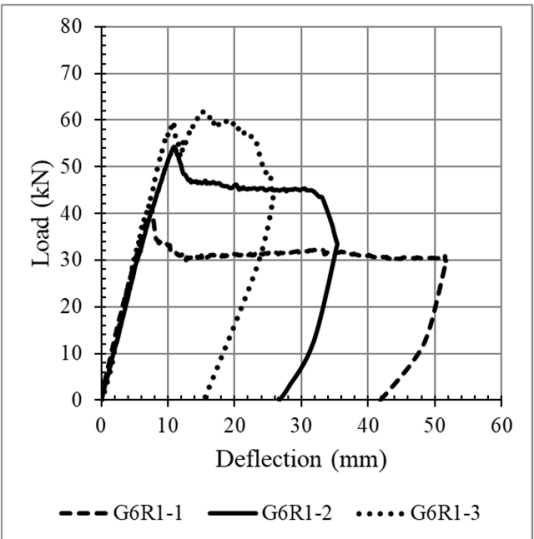

(b) Specimen strengthened with one steel bar

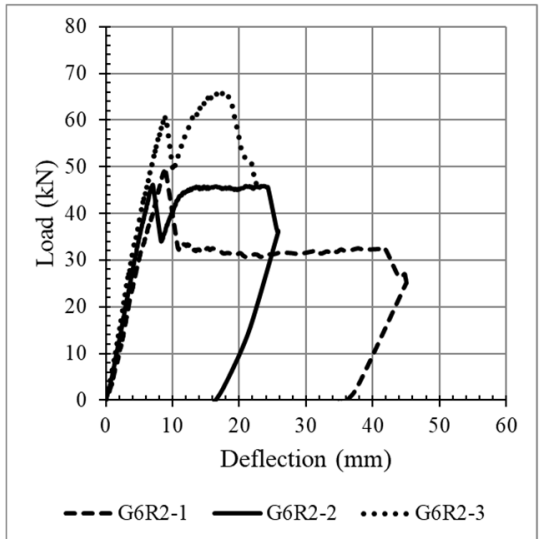

(c) Specimen strengthened with two steel bars

Fig. 5. Load-deflection curves of the tested beams.

In addition, it can be seen from these curves that the higher the number of steel bars used to strengthen, the more sudden the debonding failure will occur. In addition, it can be seen from these curves that the higher the number of steel bars used to strengthen, the more sudden the debonding failure will occur. But it can be 
seen that the capacity of the strengthened beams is proven to be higher than that of the control beams.

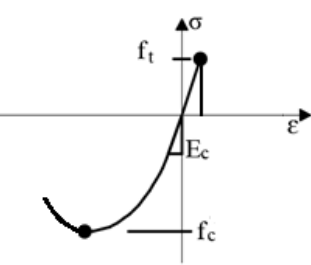

(a) Concrete

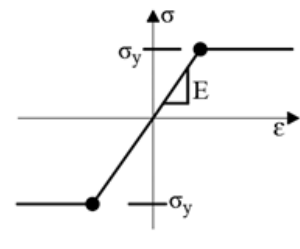

(b) Steel

Fig. 6. Stress-strain laws of concrete and steel used in the analytical study.

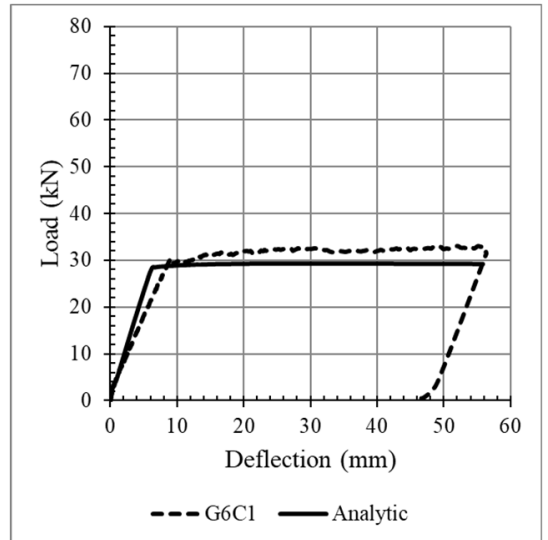

(a) $\mathrm{G} 6 \mathrm{Cl}$

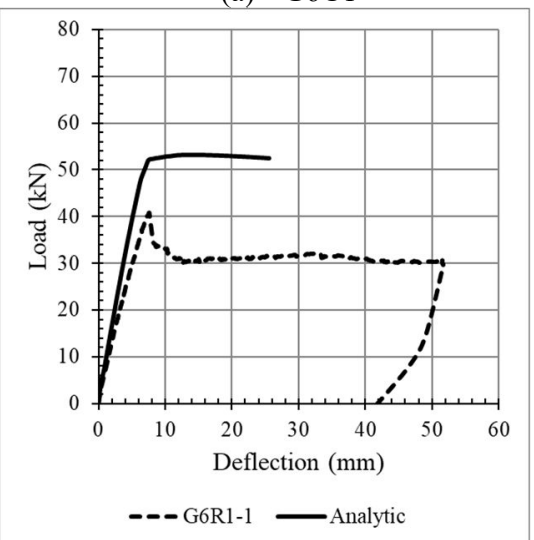

(d) G6R1-1

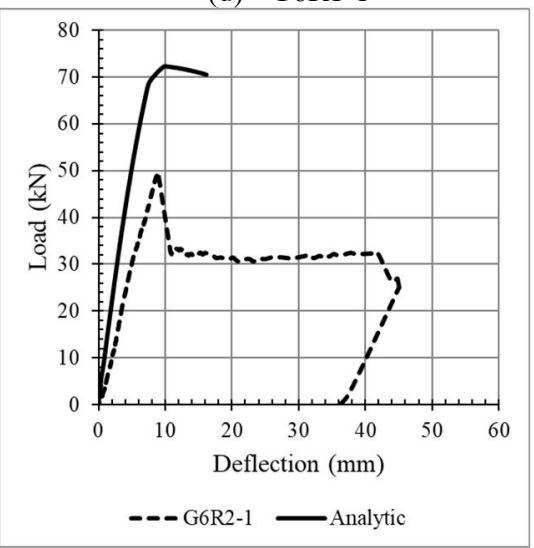

(g) G6R2-1

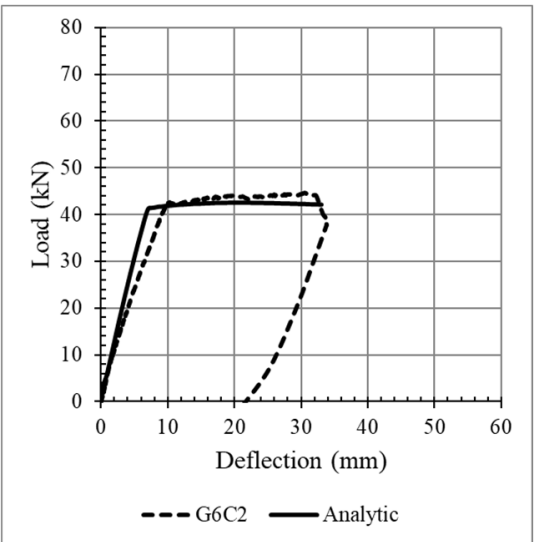

(b) $\mathrm{G} 6 \mathrm{C} 2$

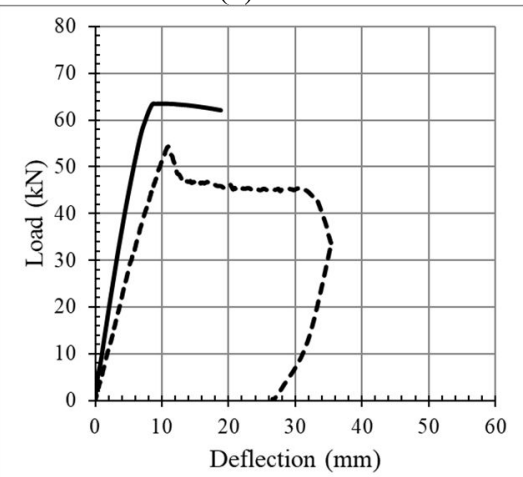

---G6R1-2 —Analytic

(e) G6R1-2

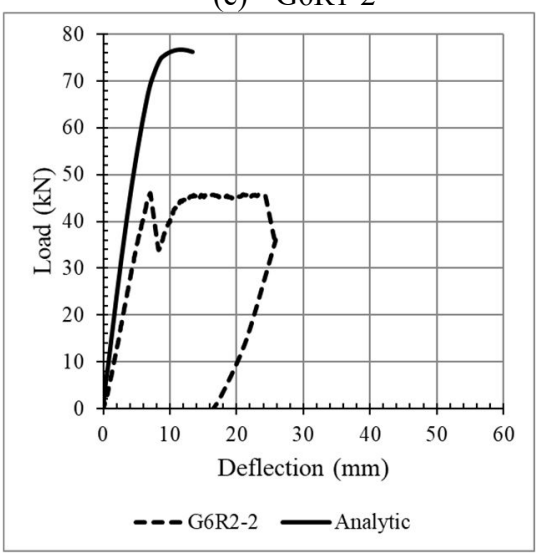

(h) G6R2-2

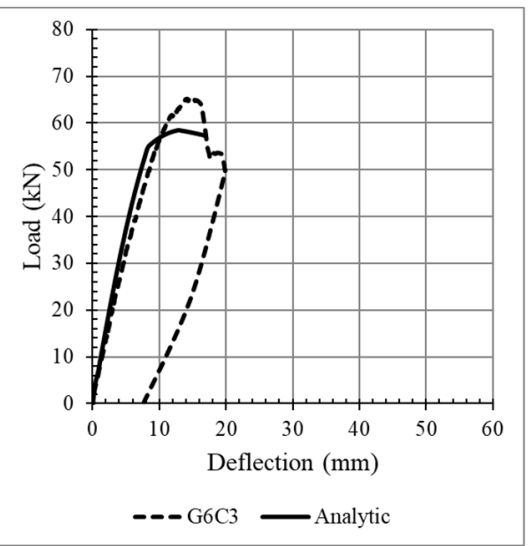

(c) $\mathrm{G} 6 \mathrm{C} 3$

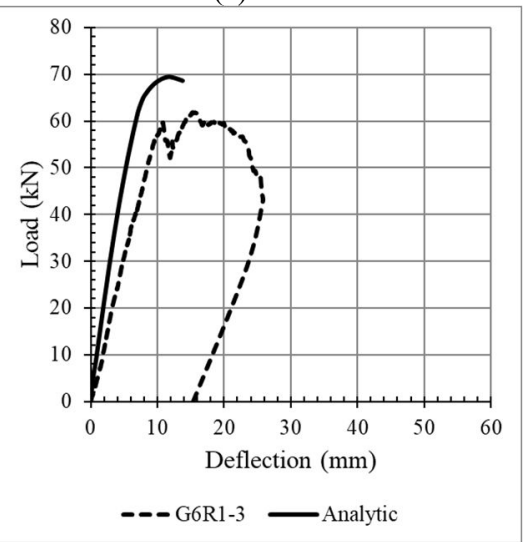

(f) G6R1-3

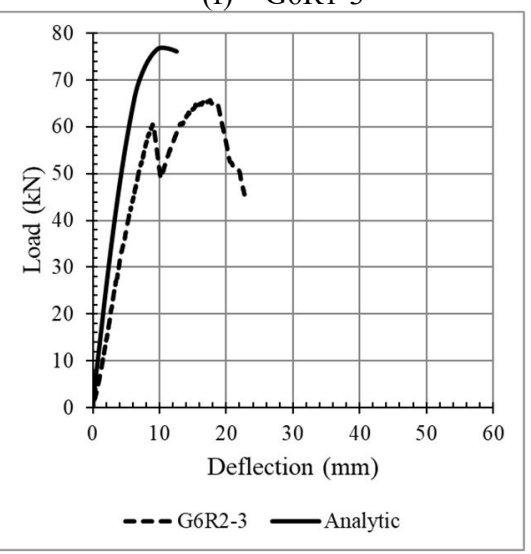

(i) G6R2-3

Fig. 7. Comparison between analytical and test results. 


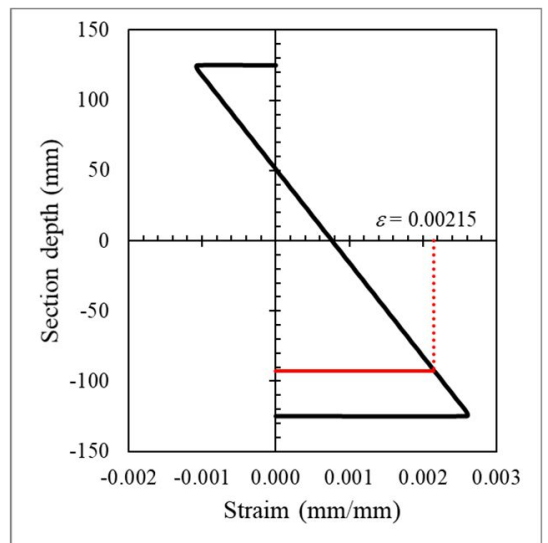

(a) Control beams (G6C1)

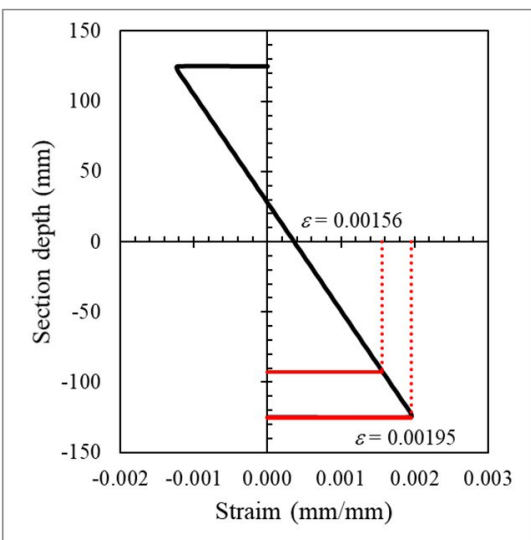

(b) Specimen strengthened with one steel bar (G6R1-1)

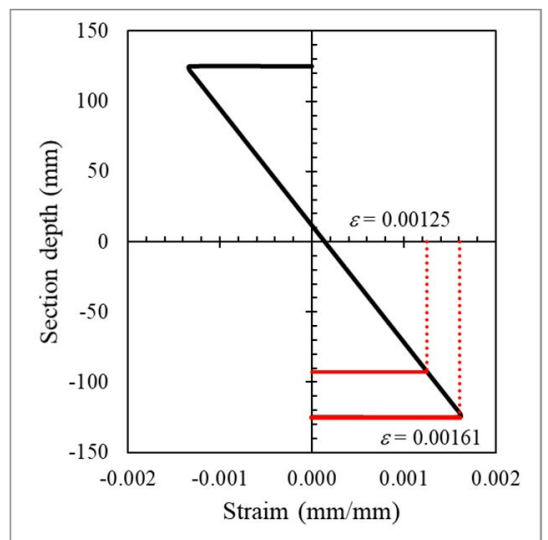

(c) Specimen strengthened with two steel bars (G6R2-1)

Fig. 8. The plot of strain distribution of the cross-section was obtained from computation results.

Fig. 8 shows the plot of strain distribution of the cross-section of specimens G6C1, G6R1-1, and G6R21 obtained from computation results. The plotted strain distribution diagrams have occurred at the yield stress level of the tensile reinforcement for the $\mathrm{G} 6 \mathrm{C} 1$ specimen and the debonding failure load level for the G6R1-1 and G6R2-1 specimens. As shown in the stress distribution above, the compressive stress at the load level taken has not reached the maximum strain value assumed in the analytical study (0.005).

As is known from the yield stress values of tensile reinforcement and strengthening steel bar, the yield strain for each reinforcement is 0.0022 and 0.0024 , respectively. The strain distribution shown in Fig. 8 proves that the strain in the strengthening bar and tensile reinforcement at debonding failure was not experience yielding. Since the strengthening steel bars have not yielded at the time of debonding failure, the tensile capacity of the steel bars has not been fully utilized. This may be avoided by reducing the diameter of the steel bar used as a strengthening. In addition, the strain that occurs in the reinforcement decreases with an increase in the amount of strengthening bar.

\section{Conclusions}

Nine reinforced concrete beams with and without strengthening were tested experimentally in this study. An analytical study was also carried out to obtain the theoretical capacity of the beams. Based on the test results, the main conclusions that can be drawn are:

1. Strengthening of reinforced concrete beams with the NSM method can increase the flexural capacity of the beam.

2. A strengthening steel bar increases the load level of the first flexural crack in the beam.

3. The strain that occurs in tensile reinforcement decreases with an increase in the amount of strengthening steel bars.
4. The area of steel bars used as strengthening must be determined as appropriately as possible to avoid premature debonding failure.

The authors express their appreciation to the Faculty of Engineering, Andalas University, for the financial support through the 2021 Faculty of Engineering Publication Grant.

\section{References}

1. BB Adhikary, H. Mutsuyoshi, Sano, M., Constr. Build. Mater., 14, 5, 237-244 (2000)

2. L.D. Lorenzis, A. Nanni, ACI Structural J., 98, 1, 60-68 (2001)

3. R. El-Hacha, S.H. Rizkalla, ACI Structural J., 101, 5, 717-726 (2004)

4. Z. Kálmán Szabó, L. Balázs, G, Periodica Polytechnica Civil Eng., 51, 1, 33-38 (2007)

5. P Sabol, S. Priganc, Procedia Eng., 65, 364-369 (2013)

6. A. Parvin, T. Syed Shah, Polymers. 8, 8, 298 (2016)

7. R. Thamrin, Sari, R.P., Procedia Eng., 171, 11291136 (2017)

8. R. Thamrin, MATEC Web of Conf., 103, 02012 (2017)

9. R. Thamrin, J. Eng. Sci. Technology. 13, 37813794 (2018)

10. R. Thamrin, S. Haris, Zaidir, MATEC Web of Conferences 276, 01004 (2019)

11. R. Thamrin, S. Haris, Zaidir, IOP Conf. Series: Materials Science, Engineering, 771, 012053 (2020)

12. R. Thamrin, Z. Zaidir, S. Desharma, Polymers. 13, 16, 2738 (2021)

13. R. Park, T. Paulay, Reinforced Concrete Structures, John Wiley, New York (1975)

14. J.B. Mander, M.J.N. Priestley, and R. Park, J. of Structural Engineering, 114, 8, 1804-1826 (198 